\title{
Investigating occupational stress among bus drivers in Universiti Teknologi Malaysia, Johor
}

\author{
Nur Azizah Arryanie Morshidi ${ }^{1}$, and Norafneeza Norazahar ${ }^{1,2 *}$ \\ ${ }^{1}$ School of Chemical and Energy Engineering, Faculty of Engineering, Universiti Teknologi \\ Malaysia, 81310 Johor Bahru, Johor, Malaysia. \\ ${ }^{2}$ Centre of Hydrogen Energy, Institute of Future Energy, Universiti Teknologi Malaysia, 81310 Johor \\ Bahru, Johor, Malaysia.
}

\begin{abstract}
This paper presents a study of occupational stress experienced by bus drivers in Universiti Teknologi Malaysia (UTM). The objectives of the study are i) to identify contributing factors leading to high stress among bus drivers and ii) to investigate the effect of occupational stress on bus drivers. A set of questionnaires consisting of demographic information, stressors leading to occupational stress, and strain of occupational stress was distributed to fifteen bus drivers working in UTM. The study used Statistical Package for the Social Sciences (SPSS) to analyse the data and correlation between the contributing factors and occupational stress among the bus drivers. Poor design of bus seat was identified as the leading factors to occupational stress among bus drivers. The bus drivers felt uncomfortable seating and driving for long hours. The seat is not ergonomic to bus driver's back and body frame. Fatigue, headache, and dizzy are common effects of occupational stress to the bus drivers.
\end{abstract}

\section{Introduction}

Occupational stress can be defined as the working environment or nature causing stress to workers [1]. In the pursuit for excellence and job demand, some workers in the manufacturing sector are experiencing occupational stress, which includes the upper and lower positions. Poor worker's abilities and inadequate knowledge to match the higher demand, as well as the situation of work environment could also be categorised in occupational stress [2].

Five major sources of occupational stress are factors intrinsic to the job, employee's roles in an organisation, video display terminal (VDT) stress, relationship at the workplace, and career development [3,4]. According to [5], the categories of stressors are task demand, physical demand, and interpersonal demand. Worker's psychological condition, socioeconomic status, and family factors could contribute to occupational stress [6]. Less

"Corresponding author: norafneeza@utm.my 
physical activity and unhealthy eating habit could cause occupational stress, particularly for workers who are scheduled to work according to rotational shift. Global economy slowdown could also contribute to occupational stress among workers [7].

According to [15], at the extreme, high demand in job task and low control on these conditions are associated with heart and cardiovascular problems, anxiety and depression, and involved in misuse of drugs.

Much research has been done involving professional drivers and it can be concluded that professional drivers are among those with the highest level that experienced workrelated psychosocial risk [8]. Occupational stress is associated with driver's behavioural changes and their work behaviour [9]. Occupational stress contributes to bad driving behaviour, which leads to accidents [10]. Fatigue is one of the most significant contributors to bad driving habit [11]. 51\% of professional drivers of large vehicles felt tired during their trips [12]. The number of fatalities involving road users are increasing year by year as vehicle ownership is increasing.

The Malaysian government and society are concerned with the increasing number of workers suffering from occupational stress at the workplace [6]. Occupational stress has been identified as one of the most crucial problems in an organisational system in Malaysian since job demand and work expectation are increasing day by day. Occupational stress can affect worker's health conditions [13].

\section{Questionnaire}

The questionnaire used was based on the National Institute for Occupational Safety and Health (NIOSH) generic job stress questionnaire adjusted to suit bus driver's field of work. The first part of the questionnaire consists of bus driver's demographic data such as gender, age, marital status, height, and weight. The second part focuses on the leading factors of occupational stress among bus drivers in Universiti Teknologi Malaysia (UTM). The questions in the second part are related to stressors in particular work environment, ergonomic, organisational, psychosocial factors, socio-economic, and family matters [14]. The third part of the questionnaire is related to their job performance and health conditions. The health conditions of bus drivers are based on stress symptoms, which include mental and somatic symptoms along with sleep disorder [14]. Meanwhile, job performance includes absenteeism, job satisfaction, and intention to leave the job [13]. In addition, bus drivers were asked about their involvement in road incidents such as accidents, traffic tickets, or penalties for the last two years, and their driving behaviour questions were based on Driver Behaviour Questionnaire (DBQ) [11]. The IBM SPSS Statistic programme was used to analyse the completed questionnaires and Cronbach's alpha was used to test the reliability of the acquired results. Most of the participants answered the questionnaires within $15 \mathrm{~min}$. 


\section{Results}

\subsection{Background information}

15 participants of this study are male. $60 \%$ of the bus drivers have normal body mass index (BMI) and another $40 \%$ are in the overweight category. The bus drivers drove more than 20 $\mathrm{km}$ in a day and they worked for more than $9 \mathrm{~h}$. Most of the bus drivers are between 26 and 33 years old, which represents $46.7 \%$ percent of the bus drivers. Only three bus drivers are above 41 years old.

\subsection{Stressors of occupational stress}

From the descriptive statistical analysis using SPSS, in the category of working environment or condition stressors, majority of the respondent agreed with the second question regarding noise issues while driving the bus than other questions. Physical environment is an extreme physical condition, which includes noise and heat as the sources of occupational stress [7]. According to [14], stressful work environment such as loud noise could contribute to occupational stress. Physical surroundings such as noise and lightings have been tested and found to be the contributing factors of occupational stress [6].

The question of ergonomic stressor shows that the seat is uncomfortable for the bus drivers because they have to sit for long hours while driving. All bus drivers participated in the study have same problems; uncomfortable seating and driving on a seat with poor design. The characteristics of seat and the materials used for the bus seat were found to cause occupational stress among UTM bus drivers.

13 of the bus drivers agreed that long working hours is the cause of stress during working. Working as a bus drivers requires them to work even during public holiday and personal leave. Occupational stress is caused by organisational aspects which include long working hours and lack of organisational support. Irregular working schedule and long working hours are two stressors for occupational stress [11].

Psychosocial factors such as frequent observation from the upper management are also leading factors to stress. Lack of recognition and self-esteem contribute to occupational stress as well [14].

Last stressor is socioeconomic and family matters. Many bus drivers have a second job such as Grab drivers, product's agent or doing online business. Table 1 shows the overall descriptive statistical analysis for Section B of the questionnaire.

Table 1. Descriptive statistics for each category in Section B.

\begin{tabular}{|c|c|}
\hline Stressors & $\begin{array}{c}\text { Descriptive } \\
\text { Statistics }\end{array}$ \\
\hline Work Environment or Condition & 2.52 \\
\hline Ergonomics & 3.75 \\
\hline Organisational Support & 2.32 \\
\hline Psychosocial Factor & 1.39 \\
\hline Socioeconomic and Family Matters & 2.13 \\
\hline
\end{tabular}




\subsection{Strain of occupational stress}

In health category, most of the bus drivers have stress symptoms such as easily fatigued while working, as well as suffering from headache, and dizziness. These symptoms show that most of the bus drivers are stress due to their job. According to [16], people who are working in a stressful condition often have stress symptoms such as being tired and lack of energy, besides back pain and cardiovascular diseases. Figure 1 shows the overall symptoms that the bus drivers experienced due to occupational stress.

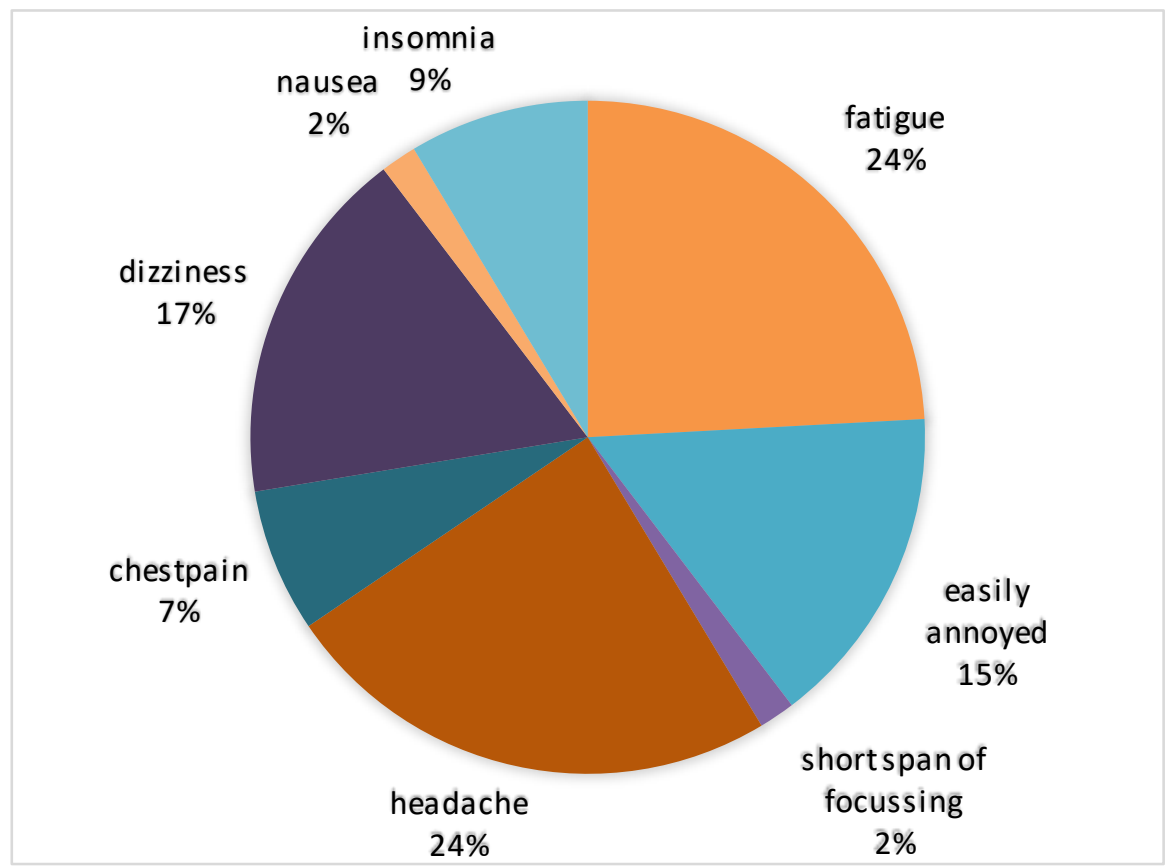

Fig. 1. Symptoms of occupational stress experienced by bus drivers.

For the job performance of bus drivers, with a mean of 3.1333, 13 bus drivers agreed that the first statement refers to their satisfaction with their current job and another two drivers strongly agreed with the statement. Majority of the bus drivers disagreed to quit their job as bus drivers. There is no record of absenteeism among the bus drivers because they never took leave without any approval from the upper management. Only four of the bus drivers had taken emergency leave due to family matters.

\subsection{Driver behaviour questionnaire}

Section D of the questionnaire is related to bus driver's driving behaviour and road violation that they had committed for the past two years. The most common driving behaviour by the bus drivers is driving even though they are tired and fatigued. Other than that, they frequently pull the brake spontaneously during peak hours. Figure 2 shows the overall driving behaviours of the bus drivers in UTM. 
All of the bus drivers did not involve in any incident or accident for the past two years, as well as in causing an accident. Unfortunately, seven bus drivers received tickets for speeding and driving at the emergency lane on a highway.

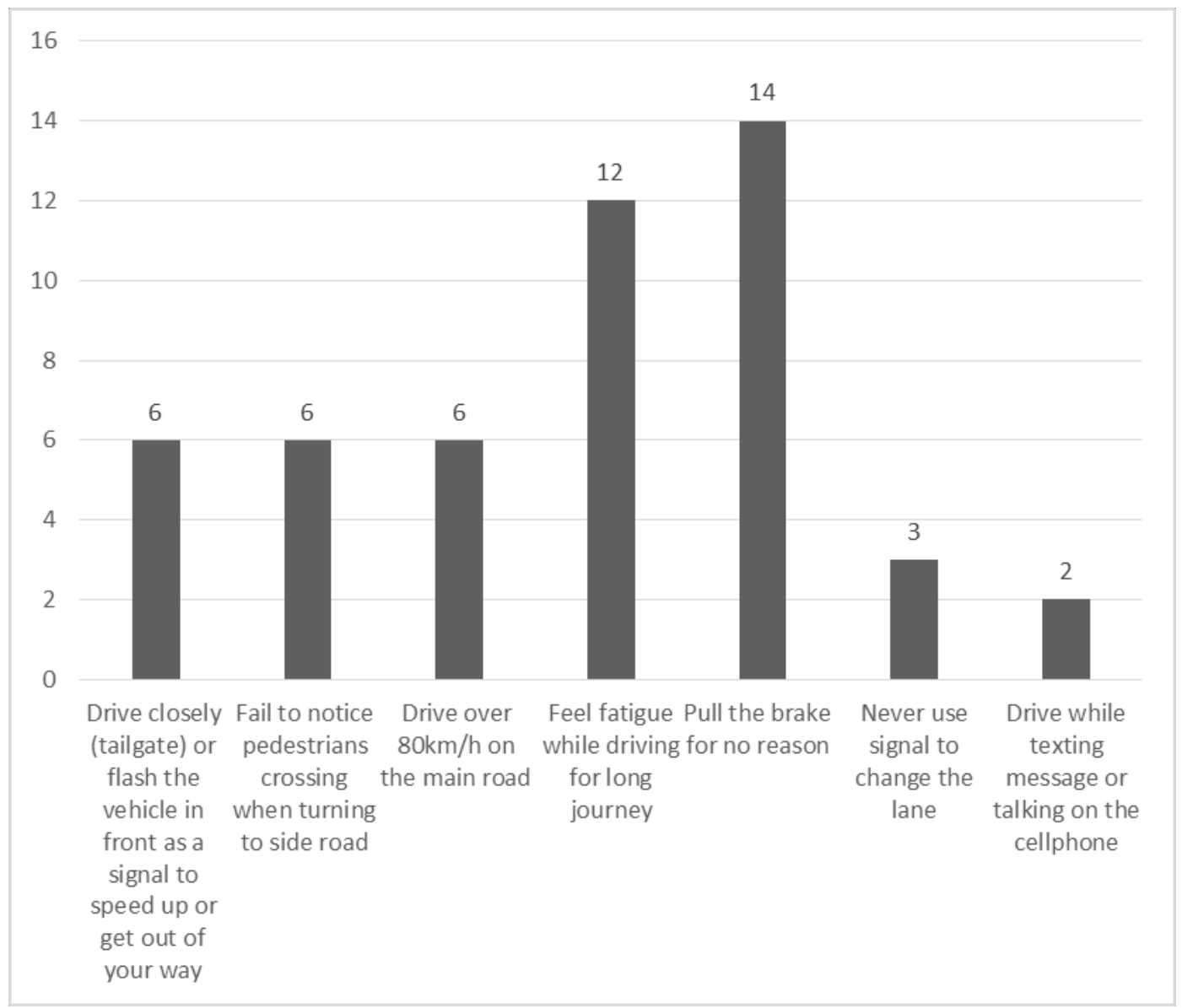

Fig. 2. Driving behaviour of UTM's bus drivers.

\section{Conclusion}

As a conclusion, the leading factors for occupational stress among bus drivers are ergonomic stressors, i.e. the condition of seat is uncomfortable due to long hours of sitting. The most significant effects of occupational stress to bus drivers are easily fatigued even when they remained seated for the whole time, feeling headache, and dizziness. However, occupational stress did not affect the bus driver's work performance and did not leading to accidents in the university's compound.

There are several limitations in this study that need to be addressed. First, the size of sample only consists of small population among bus drivers in UTM, which limits the generalisability and reliability of the results. Second, some of the respondent were not forthcoming in expressing their feelings and experiences, and subsequently creating biases 
in the questionnaire answers. The questionnaire cannot extract all data and information from the participant's feedback.

Some recommendations can be suggested in this study in order to achieve a more reliable result for future undertaking. The first recommendation is by adding more variables or factors in the questionnaire as occupational stress can be caused by other factors in psychosocial or socioeconomic factors. Next, the focus should be on a bigger sample size to achieve reliable and more diffuse results and findings. Lastly, it is recommended to add an open-ended question at the end of questionnaire, which can strengthen the data obtained as the respondents can make their own comments and explain their answers without any restriction.

The authors would like to acknowledge Ministry of Higher Education (MOHE) and Universiti Teknologi Malaysia (UTM) for the financial support. The cost centre number of the research funding is Q.J130000.2646.15J46 (Ref. No: PY/2017/02030).

\section{References}

[1] Rohany N. 2003. Isu-isu kaunseling dan perkembangan kerjaya. Kuala Lumpur:Utusan publication and distributors Sdn Bhd.

[2] Lazarus R.S., Deese J., and Osier J.F. 1993. The effects of psychological stress upon performance. Psychological Bulletin 49. 5: 293-316.

[3] Cooper C.L., Cooper R.D., and Eaken L.H. 1988. Living with stress. Penguin Books. London.

[4] Hedge A., Erikson W.A., and Rubin G. 1992. Effects of personnel and organizational factors and sick building syndrome in air-conditioned offices. In Quick J.C., Murphy. L.R., and Hurrell J.J. (Eds). Stress and well being at work. American Psychological Association. Washington D.C. 286-298.

[5] Quick J.C., and Quick J.D. 1984. Occupational stress and preventive management. McGraw Hill. New York.

[6] Manshor A.T., Fontaine R., Chong S.C. 2003.ocuupational stress among managers: A Malaysia survey. Journal of Managerial Psychology. 18(6): 622-628.

[7] Yunus J.M., Mahajar A.J. 2011. Stress and psychological well-being of government officers in Malaysia. The Journal of Human Resource and Adult Learning. 7(2): 40-50.

[8] Cendales B., Useche S.A., Gomez V. 2014. Psychosocial work factors, blood pressure and psychological strain in male bus operators. Industrial Health. 52: 279-288.

[9] Fida R., Paciello M., Tramontano C., Fontaine R.G., Barbaranelli C., Farnese M.L. 2015. An integrative approach to understanding counterproductive work behavior: the roles of stressors, negative emotions, and moral disengagement. J. Bus. Ethics. 130(1): 131-144.

[10] Kontogiannis T. 2006. Patterns of driver stress and coping strategies in a Greek sample and their relationship to aberrant behaviors and traffic accidents. Accid. Anal. Prev. 38(5): 913-924.

[11] Useche S.A., Ortiz V.G., Cendales B.E. 2017.stress-related psychosocial factors at work, fatigue, and risky driving behaviour in bus rapid transport (BRT) drivers. Accident Analysis and Prevention. 104(2017): 106-114.

[12] Amundsen A., and Sagberg F. 2003. Hours of Service Regulations and the Risk of Fatigue and Sleep-related Road Accidents: A Literature Review. Transportøkonomisk Institutt (TØI). Oslo. 
[13] Yahaya A., Yahaya N., Amat F., Bon A.T., and Zakariya Z. 2010. The effect of various modes of occupational stress, job satisfaction, intention to leave, and absentism companies commission of Malaysia. Australian Journal of Basic and Applied Sciences.

[14] Kloimüller I., Karazman R., Geissler H., Karazman-Morawetz I., and Haupt H. 1999. The relation of age, work ability index and stress-inducing factors among bus drivers. International Journal of Industrial Ergonomics. 25(2000): 497-502.

[15] Barbara, J.S.; Psych, C. and Shain, M. (2002), When Workplace Stress Stifles Productivity, Drake Business Review, 1(1): 27-29. Retrieved from http://www.drakeintl.com/dbr/pdf/work_place_stress.pdf

[16] Lluminari, Inc. 2004. Creating Healthy Corporate Cultures for Both Genders: A National Employee Survey, A Lluminari Landmark Study. 